\title{
Annelere Verilen Eğitimin Tamamlayıcı Beslenme Üzerine Etkisi
}

\author{
Impact of Maternal Education on Complementary Feeding
}

\author{
Gizem Aytekin Şahin ${ }^{1}$, Neşe Kaya ${ }^{2}$, Meda Kondolot ${ }^{3}$
}

Geliş tarihi/Received: 11.11.2019 • Kabul tarihi/Accepted: 30.12.2019

\section{ÖZET}

Amaç: Bu çalışmada, diyetisyen tarafından verilen kapsamlı bir tamamlayıcı beslenme eğitiminin annelerin bilgi düzeyi ve tamamlayıcı beslenme uygulamaları üzerine etkisinin değerlendirilmesi amaçlanmıştır.

Bireyler ve Yöntem: Araştırmaya henüz tamamlayıcı beslenmeye başlamamış 3-5 aylık bebeği olan 83 anne dahil edilmiştir. Katılımcllar eğitim grubu ( $\mathrm{n}=42$ anne ve bebek) ve kontrol grubu ( $\mathrm{n}=41$ anne ve bebek) olmak üzere iki gruba ayrılmıştır. Verilerin toplanmasında sosyo-demografik özellikler ve tamamlayıcı beslenme konusundaki bilgi düzeyine yönelik soruları içeren anket formu kullanılmıştır. Eğitim grubundaki annelere ilk görüşmede tamamlayıcı beslenme hakkında bilgisayar destekli bir eğitim ve bilgilendirici bir kitapçı verilmiştir. Kontrol grubundaki anneler ise rutin poliklinik izlemlerinde bilgilendirilmiş ve poliklinikte kullanılmakta olan broşür verilmiştir. Anneler tamamlayıcı beslenmeye başladıklarında yapılan 2. görüşmede annelerin tamamlayıcı beslenmeye başlama nedenleri ve bebeklerine ilk olarak verdikleri tamamlayıcı besinler sorgulanmıştır. Tamamlayıcı beslenmeye başladıktan 3 ay sonra yapılan 3. görüşmede ise tamamlayıcı beslenme bilgi düzeyine yönelik sorular tekrarlanmıştır.

Bulgular: Eğitim grubundaki annelerin tamamlayıcı beslenme bilgi düzeyi puanlarının kontrol grubundan daha yüksek olduğu saptanmıştır (eğitim: 20.0, kontrol: 14.0 puan, $\mathrm{p}<0.001$ ). Ayrıca eğitim grubundaki annelerin tamamlayıcı beslenme bilgi düzeyi puanlarının ilk görüşmeye göre 3. görüşmede anlamlı şekilde arttığı belirlenmiştir (ilk görüşme: 13.0, 3. görüşme: 20.0 puan, p<0.001). Ek olarak eğitim grubunda tamamlayıcı beslenmeye 6 . ayda başlayan annelerin oranının kontrol grubundan daha yüksek olduğu görülmüştür (eğitim: \%64.3, kontrol: \%17.1, p<0.001). Eğitim grubunda tamamlayıcı besinlere tuz ve şeker ekleme oranı da kontrol grubundan daha düşük bulunmuştur $(\mathrm{p}<0.05)$.

Sonuç: Annelerin tamamlayıcı beslenme konusunda bilgi düzeylerinin artırılması ve yanlış uygulamaların önlenmesi için çocuk sağlığı izlemlerinde uygun süre ayrılarak, görsel sunularla birlikte yazılı bilgi notlarının kullanılması önemlidir.

Anahtar kelimeler: Bebek beslenmesi, tamamlayıcı beslenme, bilgi düzeyi, tamamlayıcı beslenme eğitimi

\begin{abstract} maternal nutritional knowledge and complementary feeding practices.

1. İletişim/Correspondence: Erciyes Üniversitesi, Sağlık Bilimleri Fakültesi, Beslenme ve Diyetetik Bölümü, Kayseri, Türkiye

E-posta: gizemaytekin@erciyes.edu.tr - 이 https://orcid.org/0000-0002-6620-9259
\end{abstract}

Aim: This study aimed to evaluate the effect of comprehensive complementary feeding education given by dietitian on

Subjects and method: Eighty three mothers and their 3-5 months-old infants who did not start complementary feeding were included in the study. Subjects were divided into two groups: education group ( $n=42$ mothers and infants) and control
2. Erciyes Üniversitesi, Sağlık Bilimleri Fakültesi, Beslenme ve Diyetetik Bölümü, Kayseri, Türkiye • (1) https://orcid.org/0000-0002-5947-3238

3. Erciyes Üniversitesi, Tıp Fakültesi, Çocuk Sağlığı ve Hastalıkları Anabilim Dalı, Kayseri, Türkiye - ㄴo https://orcid.org/0000-0002-1168-3228 
group ( $\mathrm{n}=41$ mothers and infants). Data was collected by a questionnaire including socio-demographic characteristics and maternal knowledge on complementary feeding. At the first interview, mothers in the education group were given a computer-assisted training and a booklet about complementary feeding. The mothers in the control group received a routine care in the outpatient clinic, and a simple brochure previously used in the outpatient clinic. In the second interview, when the mothers started complementary feeding, the reasons for starting complementary feeding and first complementary foods given to infants were questioned. In the third interview (at $3^{\text {rd }}$ months of complementary feeding), the questionnaire on maternal knowledge level on complementary feeding was repeated.

Results: Maternal knowledge level on complementary feeding in the education group was found to be higher than the control group (education: 20.0, control: 14.0 points, $\mathrm{p}<0.001$ ). It was also determined that knowledge on complementary feeding scores of mothers in the education group significantly increased at $3^{\text {rd }}$ interview compared to baseline (baseline: 13.0, $3^{\text {rd }}$ interview: 20.0 points, $p<0.001$ ). The percentage of mothers who started complementary feeding at $6^{\text {th }}$ months was higher in the education groups than control group (education: 64.3\%, control: $17.1 \%, \mathrm{p}<0.001$ ). Salt and sugar addition to complementary foods was also less frequent in the education group $(\mathrm{p}<0.05)$.

Conclusion: To increase the knowledge level of mothers about complementary feeding and to prevent improper practice, it is important to use written information notes together with visual presentations while allocating appropriate time.

Keywords: Infant nutrition, complementary feeding, knowledge level, complementary feeding education

\section{Gíriş}

Anne sütü, hem anne hem de bebek açısından kısa ve uzun dönemde birçok yararı olan, bebeğin beslenmesi için en uygun besindir (1-3). Altıncı aydan itibaren yalnızca anne sütü ile bebeğin artan enerji ve besin ögesi gereksinimlerini karşllamak mümkün olmamaktadır (4). Anne sütünün tek başına bebeğin ihtiyaçlarını karşılayamadığı bu dönemde başlatılan ve tamamen anne sütü ile beslenmeden çocuk beslenmesine geçiş yapılan dönem "tamamlayıcı beslenme dönemi” olarak adlandırılmaktadır (5). Dünya Sağlık Örgütü (DSÖ) ve Birleşmiş Milletler Çocuklara Yardım Fonu (UNICEF) her bebeğin ilk 6 ay boyunca sadece anne sütü almasinı, 6. ayda uygun şekilde tamamlayıcı beslenmeye geçilmesini ve tamamlayıcı besinlerle birlikte en az 2 yaşına kadar anne sütüne devam edilmesini önermektedir (6). Tamamlayıcı beslenmenin zamanında, yeterli, güvenli ve uygun besinlerle olması durumunda çocukluk çağı malnütrisyon oranlarının düşürülmesi, uygun büyüme-gelişmenin sağlanması ve birçok kronik hastalığın önlenmesi mümkün olmaktadır $(7,8)$.

Türkiye Nüfus ve Sağlık Araştırması (TNSA) 2018 verilerine göre ülkemizde emzirme yaygın bir uygulamadır. Ancak yaşamın ilk 4-5 ayında tek başına anne sütü ile beslenme oranı \%14’tür ve bebeklere erken aylardan itibaren bebek formülü verilmektedir (9). Bununla birlikte literatürde tamamlayıcı beslenmeye erken veya geç başlamanın bebek açısından bazı olumsuz sonuçları olabileceği belirtilmektedir $(10,11)$. Tamamlayıcı beslenmeye erken başlamak genellikle alerji, demir eksikliği anemisi ve tip 1 diyabet ile (10), geç başlamak ise yetersiz büyüme ve gelişme ile ilişkilendirilmiştir (11,12). Bu şekilde uygun olmayan tamamlayıcı beslenme uygulamaları genellikle annelerin/ bakıcıların bilgi eksikliğinden ve yanlış geleneksel inanışlarından kaynaklanmaktadır (12). Bu durumun düzeltilmesi için annelere ayrıntılı tamamlayıcı beslenme eğitimleri verilerek bilgi düzeylerinin artırılması önemlidir (13).

Ülkemizde annelerin anne sütü ve tamamlayıcı beslenmeileilgilibilgidüzeyleri,inançveuygulamaları üzerine yapılan birçok kesitsel çalışma mevcuttur (1418), ancak annelere verilen anne sütü ve tamamlayıcı beslenme eğitiminin etkinliğini araştıran müdahale çalışmaları sınırlıdır $(19,20)$. Bu çalışmada annelere verilen tamamlayıcı beslenme eğitiminin annelerin bilgi düzeyi ve tamamlayıcı beslenme uygulamaları üzerine etkisini değerlendirmek amaçlanmıştır. 


\section{BIRREYLER VE YÖNTEM}

\section{Araştırma Yeri, Zamanı ve Örneklem Seçimi}

Bu prospektif araştırma, Erciyes Üniversitesi Mustafa Eraslan-Fevzi Mercan Çocuk Hastanesi Sağlam Çocuk Polikliniği’nde yapılmıştır. Örneklem büyüklüğünün hesaplanmasında daha önce İşgör ve ark. (19) tarafindan yapılan çalışmadan faydalanılmıştır. Annelerin tamamlayıcı beslenme bilgi düzeyindeki değişim \%5 olarak planlanmış, \%80 güç ve $\% 95$ güven düzeyinde güç analizi yapılmış, eğitim grubuna 25 , kontrol grubuna 25 olmak üzere, toplam 50 anne ve bebeğinin çalışmaya dahil edilmesi uygun görülmüştür. İzlem sırasında oluşabilecek kayıplar göz önünde bulundurularak her iki gruba da 50'şer anne ve bebeğinin dahil edilmesi planlanmıştır. Araştırmaya zamanında doğmuş, tekil gebelik ile dünyaya gelmiş, normal doğum ağırlığına sahip, doğumsal bir anomalisi ve herhangi bir kronik ve metabolik hastalığı olmayan ve yalnızca anne sütüyle beslenen 3-5 ay arasindaki bebekler ile herhangi bir kronik ve metabolik hastalığı olmayan, çekirdek aileye sahip, daha önce tamamlayıcı beslenme ile ilgili bir eğitim almamış ve çalışmaya katılmaya gönüllü olan anneler dâhil edilmiştir. Anne ve bebekleri eğitim grubu ( $n=50)$ ve kontrol grubu $(n=50)$ olarak iki gruba ayrılmıştır. İzlem sırasında eğitim grubundaki annelerden biri tip 1 diyabet tanısı aldığı için çalışma dışında bırakılmıştır. Kontrol grubunda bebeklerden birinde yutma güçlüğü, bir bebekte yumurta alerjisi ortaya çıktığı için çalışmadan çıkarılmıştır. Ayrıca eğitim grubundan 5, kontrol grubundan 7 anne çalışmaya devam etmek istemediği için çalışma, eğitim grubundan 42, kontrol grubundan ise 41 anne ve bebek ile tamamlanmıştır.

Çalışmaya başlamadan önce Erciyes Üniversitesi Tıp Fakültesi Klinik Araştırmalar Etik Kurulu'ndan 2016/85 karar numaralı etik kurul izni alınmıştır. Katılımcllar Helsinki Deklarasyonu'na uygun olarak araştırma konusunda bilgilendirilmiş, onam formu imzalatılmıştır.

\section{Verilerin Toplanması ve Değerlendirilmesi}

Verilerin toplanmasinda sosyo-demografik özellikler ve “Tamamlayıcı Beslenme Bilgi Düzeyi” sorularını içeren anket formu çalışma başlangıcında araştırmacılar tarafından yüz yüze uygulanmıştır. Çocuk sağlığı izlemlerinin ardından eğitim grubundaki annelere "Anneler için Tamamlayıcı Beslenme Eğitimi” yapılmış, örnek tamamlayıcı besin tarifleri sunulmuş ve "Tamamlayıcı Beslenme Kitapçığı” verilmiştir. Kontrol grubundaki anneler ise sağlam çocuk poliklinik izlemlerinde verilen rutin beslenme eğitimi ve bilgi broşürü ile izlenmiştir.

Anneler tamamlayıcı beslenmeye başladıkları zaman (bebeklerin yaşı 3-7 ay arasında iken) yapılan 2. yüz yüze görüşmede annelerin tamamlayıcı besinlere başlama nedenleri ve bebeklerine ilk olarak verdikleri besinler sorgulanmıştır. Anneler tamamlayıcı beslenmeye başladıktan 3 ay sonra (bebeklerin yaşı 6-10 ay arasında iken) ise üçüncü yüz yüze görüşme yapılmış, “Tamamlayıcı Beslenme Bilgi Düzeyi” soruları tekrar sorulmuş, tamamlayıcı besinlere tuz, şeker, baharat ekleme durumları sorgulanmıştır. Bebeklerin boy uzunluğu ve vücut ağırlığı ölçümleri araştırmacı tarafından tekniğine uygun olarak (21) yapilmıştır.

Annelerin tamamlayıcı beslenme konusundaki bilgi düzeylerini ölçmek için DSÖ (6), Amerikan Pediatri Akademisi (American Academy of Pediatrics, AAP) (22) ve T.C. Sağlık Bakanlığı (23) rehberlerinden derlenerek oluşturulmuş 25 soruluk bir anket formu hazırlanmıştır. Anneler sorulara "doğru" veya "yanlış” olarak cevap vermişlerdir. Sorular, annelere araştırmacı tarafından sorulmuş ve işaretlenmiştir. “Tamamlayıcı Beslenme Bilgi Düzeyi” anketi Tablo 1'de verilmiştir.

Tamamlayıcı beslenme konusundaki bilgi düzeylerini artırmak amacıyla eğitim grubundaki 42 anne tek başına ayrı bir odaya alınarak, DSÖ (6), AAP (22) ve T.C. Sağlık Bakanlığı rehberlerinden (23) derlenerek 
Tablo 1. Tamamlayıcı beslenme bilgi düzeyi anketi

\begin{tabular}{|c|c|c|}
\hline Bilgi Düzeyi Soruları & Doğru & Yanlış \\
\hline 1. Bebek doymuyorsa 6 . aydan önce tamamlayıcı besin verilebilir. & & $\mathrm{x}$ \\
\hline 2. Anne, sütünün az geldiğini düşünüyorsa bebek kaç aylık olursa olsun tamamlayıcı besin verebilir. & & $\mathrm{x}$ \\
\hline 3. Bebeğin farklı tatlara alışması için 6.aydan önce az miktarda besin verilebilir. & & $\mathrm{x}$ \\
\hline 4. Farklı besinler bebeğin beslenmesine yavaş yavaş eklenmelidir. & $\mathrm{x}$ & \\
\hline 5. Bebek bir besine alıştıktan birkaç gün sonra yeni besine geçilmelidir. & $\mathrm{x}$ & \\
\hline 6. Tamamlayıcı besinlere tuz, şeker ve baharat eklenmesinde bir sakınca yoktur. & & $\mathrm{x}$ \\
\hline 7. Besinler kaşık ya da bardak yerine biberonla verilmelidir. & & $\mathrm{x}$ \\
\hline 8. Bebeklere besinler plastik kaplarla verilebilir. & & $\mathrm{x}$ \\
\hline 9. Meyve püresi meyve suyundan daha besleyicidir. & $\mathrm{x}$ & \\
\hline 10. Mercimek gibi kuru baklagillerin ete benzer yararları vardır. & $\mathrm{x}$ & \\
\hline 11. Bebeğin yemekleri günlük hazırlanmalıdır. & $\mathrm{x}$ & \\
\hline 12. Bebek beslenmesinde hazır ve konserve besinler kullanılabilir. & & $\mathrm{x}$ \\
\hline 13. Bebeğe 6. aydan itibaren bal verilebilir. & & $\mathrm{x}$ \\
\hline 14. Üç yaşına kadar kuruyemiş gibi sert kabuklu besinler bebeğe verilmez. & $\mathrm{x}$ & \\
\hline 15. Yemeklerin suyu çok besleyicidir, (ekmek banarak) bebeğe verilmelidir. & & $\mathrm{x}$ \\
\hline 16. Bebeğe bir yaşına kadar et verilmez. & & $\mathrm{x}$ \\
\hline 17. Et yerine bebeğe et suyu, kemik suyu verilmesi daha uygundur. & & $\mathrm{x}$ \\
\hline 18. Pastörize süt yerine sokak sütü tercih edilmelidir. & & $\mathrm{x}$ \\
\hline 19. Keçi sütü inek sütünden daha besleyicidir. & & $\mathrm{x}$ \\
\hline 20. Bebeğe 8. aydan itibaren pastörize peynir verilebilir. & $\mathrm{x}$ & \\
\hline 21. Bebek için hazırlanan besinler iki saatten daha fazla oda sıcaklığında bekletilmemelidir. & $\mathrm{x}$ & \\
\hline 22. Bebeğe verilecek besinler blenderdan geçirilerek tamamen pürüzsüz hale getirilmelidir. & & $\mathrm{x}$ \\
\hline 23. Bebeğe haşlanmış yumurta verilecek ise az pişirilmelidir. & & $\mathrm{x}$ \\
\hline 24. Bebeğe ilk aylardan itibaren kaynatılmış su verilmelidir. & & $\mathrm{x}$ \\
\hline 25. Bebeğe çay verilebilir. & & $\mathrm{x}$ \\
\hline
\end{tabular}

oluşturulmuş, 20 dakikalık bilgisayar destekli “Anneler için Tamamlayıcı Beslenme Eğitimi” bireysel olarak yapılmış ve aylara göre bebeklere verilebilecek örnek tamamlayıcı besin tarifleri gösterilmiştir. Daha sonra sunumda anlatılan bilgilerin bir özeti niteliğinde olan “Tamamlayıcı Beslenme Kitapçı̆̆ı” verilmiştir.

\section{Verilerin İstatistiksel Değerlendirilmesi}

Verilerin değerlendirilmesinde Sosyal Bilimler için İstatistik Paket Programından (versiyon 22.0, USA, IBM Corp., 2013) yararlanılmıştır. Verilerin dağılımı Shapiro-Wilks testi ile incelenmiştir. Kategorik değişkenler için sayı (S), yüzde (\%), sayısal değişkenler için ortalama $(\overline{\mathrm{X}})$, standart sapma (SS) ve ortanca değerleri verilmiştir. Bağımsız iki grup oranlarının karşılaştırılmasında ki-kare testi, ortancalarının karşılaştırılmasında Mann-Whitney U testi, bağımlı iki grup ortancalarının karşılaştırmasında Wilcoxon testi kullanılmıştır. İstatistiksel değerlendirmelerde $\mathrm{p}<0.05$ değeri anlamlı kabul edilmiştir.

\section{BULGULAR}

Tablo 2'de katılımcıların sosyo-demografik özellikleri gösterilmiştir. Yaş, eğitim düzeyi, çalışma durumu, sosyoekonomik durum ve çocuk sayısı açısından eğitim ve kontrol grubundaki anneler arasında fark bulunmamıştır ( $p>005)$. Ayrıca bebeklerin ortanca doğum ağırlığı (eğitim grubu: 3167.5 g, kontrol grubu: 3250.0 g) ve boy uzunluğu (eğitim grubu: 50.0 $\mathrm{cm}$, kontrol grubu: $50.0 \mathrm{~cm}$ ) açısından her iki grup arasında anlamlı bir fark olmadığı belirlenmiştir ( $p>0.05)$ (veriler tabloda gösterilmemiştir). 
Tablo 2. Katılımcıların sosyo-demografik özelliklerinin dağılımı

\begin{tabular}{|c|c|c|c|c|c|c|}
\hline \multirow{2}{*}{ Özellikler } & \multicolumn{2}{|c|}{ Eğitim grubu ( $n=42)$} & \multicolumn{2}{|c|}{ Kontrol grubu $(n=41)$} & \multirow{2}{*}{$X^{2}$} & \multirow{2}{*}{$\mathbf{p}$} \\
\hline & $\mathbf{S}$ & $\%$ & $\mathbf{S}$ & $\%$ & & \\
\hline \multicolumn{7}{|l|}{ Annenin yaşı (yıl) } \\
\hline $19-24$ & 5 & 11.9 & 4 & 9.8 & \multirow{4}{*}{0.166} & \multirow{4}{*}{1.00} \\
\hline $25-29$ & 18 & 42.9 & 19 & 46.3 & & \\
\hline $30-35$ & 13 & 30.9 & 12 & 29.3 & & \\
\hline $35+$ & 6 & 14.3 & 6 & 14.6 & & \\
\hline \multicolumn{7}{|l|}{ Annenin eğitim düzeyi } \\
\hline İlkokul & 6 & 14.3 & 7 & 17.1 & \multirow{4}{*}{0.605} & \multirow{4}{*}{0.895} \\
\hline Ortaokul & 4 & 9.5 & 5 & 12.2 & & \\
\hline Lise & 12 & 28.6 & 9 & 21.9 & & \\
\hline Üniversite ve üzeri & 20 & 47.6 & 20 & 48.8 & & \\
\hline Annenin çalışma durumu & & & & & 0.978 & 0.372 \\
\hline Çalışmıyor & 28 & 66.7 & 33 & 56.1 & & \\
\hline Çalışıyor & 14 & 33.3 & 18 & 43.9 & & \\
\hline \multicolumn{7}{|l|}{ Sosyo-ekonomik durum } \\
\hline Geliri giderinden az & 10 & 23.8 & 12 & 29.3 & \multirow{3}{*}{0.413} & \multirow{3}{*}{0.813} \\
\hline Geliri giderine eşit & 20 & 47.6 & 17 & 41.4 & & \\
\hline Geliri giderinden fazla & 12 & 28.6 & 12 & 29.3 & & \\
\hline \multicolumn{7}{|c|}{ Başka bir çocuğa sahip olma durumu } \\
\hline Evet & 23 & 54.8 & 21 & 51.2 & \multirow{2}{*}{0.105} & \multirow{2}{*}{0.746} \\
\hline Hayır & 19 & 45.2 & 20 & 48.8 & & \\
\hline \multicolumn{7}{|l|}{ Doğum şekli } \\
\hline Vajinal & 17 & 40.5 & 17 & 41.5 & \multirow{2}{*}{0.008} & \multirow{2}{*}{1.000} \\
\hline Sezaryen & 25 & 59.5 & 24 & 58.5 & & \\
\hline
\end{tabular}

Tablo 3. Katılımcıların tamamlayıcı beslenme bilgi düzeylerinin karşılaştırılması

\begin{tabular}{|c|c|c|c|c|c|c|}
\hline \multirow[b]{2}{*}{ Bilgi düzeyi soruları } & \multicolumn{2}{|c|}{ Eğitim grubu $(n=42)$} & \multicolumn{2}{|c|}{ Kontrol grubu $(n=41)$} & \multirow[b]{2}{*}{$\mathbf{p}^{*}$} & \multirow[b]{2}{*}{$\mathbf{p}^{\dagger}$} \\
\hline & $\begin{array}{c}\text { Başlangıç } \\
\text { Ortanca } \\
\text { (Alt-Üst) }\end{array}$ & $\begin{array}{l}\text { 3. görüşme } \\
\text { Ortanca } \\
\text { (Alt-Üst) }\end{array}$ & $\begin{array}{c}\text { Başlangıç } \\
\text { Ortanca } \\
\text { (Alt-Üst) }\end{array}$ & $\begin{array}{l}\text { 3. görüşme } \\
\text { Ortanca } \\
\text { (Alt-Üst) }\end{array}$ & & \\
\hline \multirow[t]{2}{*}{ Ortanca doğru cevap sayısı/soru sayısı } & $\begin{array}{c}13.0 / 25 \\
(2.0-21.0)\end{array}$ & $\begin{array}{c}20.0 / 25 \\
(12.0-24.0)\end{array}$ & $\begin{array}{c}12.0 / 25 \\
(4.0-20.0)\end{array}$ & $\begin{array}{c}14.0 / 25 \\
(4.0-21.0)\end{array}$ & \multirow[t]{2}{*}{0.170} & \multirow[t]{3}{*}{$<0.001$} \\
\hline & $\mathrm{p}<0.001$ & & $\mathrm{p}=0.850$ & & & \\
\hline $\begin{array}{l}\text { Eğitim sonrası ve öncesi arasında doğru } \\
\text { cevaplanan soru farkı ortancası }\end{array}$ & $\begin{array}{c}6.0 \\
(5.0-9.0)\end{array}$ & & $\begin{array}{c}0.0 \\
(-1.0-1.0)\end{array}$ & & & \\
\hline & & $\mathrm{p}<0.001$ & & & & \\
\hline
\end{tabular}

*Başlangıçta gruplar arasında bilgi düzeyinin karşılaştırılması

+Üçüncü görüşmede gruplar arasında bilgi düzeyinin karşılaştırılması

Tablo 3'te katılımcların tamamlayıcı beslenme konusundaki bilgi düzeyleri karşılaştırılmıştır. Başlangıçta eğitim ve kontrol grubu arasındaki annelerin ortanca bilgi düzeyi arasında fark olmadığı (eğitim grubu: 13.0, kontrol grubu: 12.0 puan, p=0.170), üçüncü görüşmede eğitim grubundaki annelerin ortanca bilgi düzeyinin kontrol grubundan daha yüksek olduğu görülmüştür (eğitim grubu: 20.0, 
kontrol grubu: 14.0 puan, p<0.001). Ayrıca üçüncü görüşmede eğitim grubundaki annelerin ortanca bilgi düzeyi başlangıca göre anlamlı olarak artmıştır (başlangiç: 13.0, 2. görüşme: 20.0 puan, $\mathrm{p}<0.001$ ). İki grubun eğitim sonrası ve öncesi arasında doğru cevapladığı soru farkına bakıldığında ise eğitim grubunda doğru cevaplanan soru farkı ortancasının (6.0) kontrol grubundan (0.0) anlamlı olarak daha yüksek olduğu belirlenmiştir ( $\mathrm{p}<0.001)$.

Tablo 4'te annelerin tamamlayıcı beslenmeye başlama ayları ve ilk olarak verdikleri tamamlayıcı besinler karşılaştırılmıştır. Grupların tamamlayıcı beslenmeye başladıkları ayların ortalamasına bakıldığında, eğitim grubundaki annelerin $5.5 \pm 0.6$ ayda, kontrol grubundaki annelerin ise $4.5 \pm 1.0$ ayda bebeklerine ilk tamamlayıcı besini verdiği belirlenmiştir $(\mathrm{p}=0.001)$. Tamamlayıcı besine başlama aylarının dağılımı incelendiğinde, kontrol grubundaki bebeklerin \%17.1'ine 3-4 ay arasında tamamlayıcı beslenmeye başlanırken, eğitim grubunda 4 . aydan önce tamamlayıcı beslenmeye başlanan bebek bulunmadığı görülmüştür. Eğitim grubundaki annelerin \%64.3'ü tamamlayıcı beslenmeye 6. ayda başlarken, kontrol grubunda bu oran \%17.1'dir. Eğitim grubundan bir anne ise tamamlayıcı beslenmeye 7 . ayda başlamıştır. Tamamlayıcı beslenmeye başlama zamanları açısından iki grup arasında anlamlı bir farklılık olduğu görülmüştür $(\mathrm{p}<0.001)$.

Bebeklere en sık verilen ilk tamamlayıcı besinlin her iki grupta da sırasıyla yoğurt (eğitim grubu: \%61.9, kontrol grubu: \%31.7), bebek formülü (eğitim grubu: \%11.9, kontrol grubu: \%24.4) ve meyve suyu/püresi (eğitim grubu: \%11.9, kontrol grubu: \%17.1) olduğu belirlenmiştir. Bunlara ek olarak kontrol grubundaki bebeklere ilk tamamlayıcı besin olarak verilmesi önerilmeyen tam yumurta ( $\mathrm{n}=1, \% 2.4)$, yemek suları

Tablo 4. Annelerin tamamlayıcı beslenmeye başlama zamanları ve ilk olarak verdikleri tamamlayıcı besinlerin karşılaştırılması

\begin{tabular}{|c|c|c|c|c|c|c|}
\hline \multirow{3}{*}{ Tamamlayıcı besine başlama yaşı (ay) } & \multicolumn{2}{|c|}{ Eğitim grubu $(n=42)$} & \multicolumn{2}{|c|}{ Kontrol grubu (n=41) } & \multicolumn{2}{|c|}{$\mathbf{P}$} \\
\hline & \multicolumn{2}{|c|}{$\begin{array}{l}5.5 \pm 0.6 \\
(4.1-7.0)\end{array}$} & \multicolumn{2}{|c|}{$\begin{array}{l}4.5 \pm 1.0 \\
(3.0-6.2)\end{array}$} & \multicolumn{2}{|c|}{$p=0.001$} \\
\hline & $\mathbf{S}$ & $\%$ & $\mathbf{S}$ & $\%$ & $\boldsymbol{X}^{2}$ & $\mathbf{P}$ \\
\hline \multicolumn{7}{|l|}{$\begin{array}{l}\text { Tamamlayıcı besine başlama yaşına } \\
\text { göre dağılımı (ay) }\end{array}$} \\
\hline$\geq 3-<4$ & - & - & 7 & 17.1 & & \\
\hline$\geq 4-<5$ & 3 & 7.1 & 13 & 31.7 & & \\
\hline$\geq 5-<6$ & 11 & 26.2 & 14 & 34.1 & 26.366 & 0.000 \\
\hline$\geq 6-<7$ & 27 & 64.3 & 7 & 17.1 & & \\
\hline 7 & 1 & 2.4 & - & - & & \\
\hline \multicolumn{7}{|l|}{ İlk olarak verilen tamamlayıcı besin } \\
\hline Yoğurt & 26 & 61.9 & 13 & 31.7 & & \\
\hline Bebek formülü & 5 & 11.9 & 10 & 24.4 & & \\
\hline Meyve suyu/püresi & 5 & 11.9 & 7 & 17.1 & & \\
\hline Yumurta sarısı & 5 & 11.9 & 2 & 4.9 & & \\
\hline Sebze püresi & - & - & 3 & 7.3 & & \\
\hline Tam yumurta & - & - & 1 & 2.4 & 17.610 & 0.023 \\
\hline Yemek suları & - & - & 2 & 4.9 & & \\
\hline Bebek bisküvisi & - & - & 1 & 2.4 & & \\
\hline Bal-şeker & - & - & 1 & 2.4 & & \\
\hline Pirinç unlu muhallebi & 1 & 2.4 & - & - & & \\
\hline Hurma ezmesi & - & - & 1 & 2.4 & & \\
\hline
\end{tabular}


( $\mathrm{n}=2, \% 4.9)$, bebek bisküvisi ( $\mathrm{n}=1, \% 2.4)$, bal-şeker $(\mathrm{n}=1, \% 2.4)$ gibi besinlerin de verildiği belirlenmiştir (Tablo 4).

Tablo 4.Tamamlayıcı beslenmeye 6 aydan önce başlayan annelerin tamamlayıcı beslenmeye başlama sebepleri sorgulandığında her iki grupta da benzer şekilde "bebek doymadığı için" (eğitim grubu: \%42.9, kontrol grubu: \%32.4, p=0.522), "farklı tatlara alışması için” (eğitim grubu: \%35.7, kontrol grubu: \%44.1, $\mathrm{p}=0.750$ ) ve "sütüm az geldiği için” (eğitim grubu: \%14.3, kontrol grubu: \%29.4, $\mathrm{p}=0.465$ ) yanıtları ilk üç sıradadır (veriler tabloda gösterilmemiştir).

Tablo 5'te tamamlayıcı beslenmeye başladıktan 3 ay sonra annelerin tamamlayicı besinlere tuz, baharat ve şeker ekleme durumları karşılaştırılmıştır. Her iki grup arasında tamamlayıcı besinlere tuz (eğitim grubu: \%28.6, kontrol grubu: \%61, p=0.004) ve şeker ekleme durumu (eğitim grubu: \%14.3, kontrol grubu: $\% 39, \mathrm{p}=0.013$ ) açısından anlamlı bir farklılık olduğu, baharat ekleme oranının ise her iki grupta benzer olduğu (eğitim grubu: \%7.1, kontrol grubu: \%17.1, p= 0.194) görülmüştür.

\section{TARTIŞMA}

Yaşamın ilk iki yılı uygun büyüme ve gelişme için "kritik bir pencere" olarak kabul edilmektedir. $\mathrm{Bu}$ dönemdeki beslenme uygulamaları kısa ve uzun dönemde çocukların fizyolojik, nörolojik ve psikolojik gelişimleri açısından önemlidir (24). Genellikle annelerin bilgi eksikliğinden ve toplumsal inanışlardan kaynaklanan yanlış tamamlayıcı beslenme uygulamaları, bebeklerin büyüme-gelişmesini olumsuz etkilemektedir $(12,13)$.
Verilen uygun eğitimlerle annelerin tamamlayıcı beslenme konusundaki bilgi düzeylerinin artırılması sağlanmakta ve yanlış uygulamaların önüne geçilebilmektedir (7,25). Ancak literatür incelendiğinde ülkemizde tamamlayıcı beslenme ile ilgili eğitim çalışmalarının sınırlı olduğu görülmüştür $(19,20)$. Bu nedenle bu çalışmada, annelere çocuk sağlığı izleminden sonra ayrı bir poliklinik odasında yeterli zaman ayrlarak, diyetisyen tarafindan verilen ayrıntılı bir tamamlayıcı beslenme eğitiminin annelerin bilgi düzeyi ve tamamlayıcı beslenme uygulamaları üzerine etkisinin değerlendirilmesi amaçlanmıştır.

Eğitim, annelerin tamamlayıcı beslenme konusundaki yanlış bilgi ve uygulamalarının düzeltilmesinde etkili ve düşük maliyetli bir yoldur (26). Çalışmalar, eğitim sonrasında annelerin bilgi düzeyinde anlamlı bir artış olduğunu göstermektedir (19,25,27). Bu çalışmada başlangıçta eğitim ve kontrol grubundaki annelerin tamamlayıcı beslenme bilgi düzeyleri benzerken, eğitimin verilmesinin ardından anneler tamamlayıcı beslenmeye başladıktan 3 ay sonra yapılan üçüncü görüşmede başlangıca göre bilgi düzeylerinde anlamlı bir artış olduğu görülmüştür. Kontrol grubundaki annelerin bilgi düzeyi puanlarında ise başlangıç ile 3. görüşme arasında bir fark bulunamamıştır. Ancak eğitimin etkinliğinin değerlendirilmesinde yalnızca bilgi düzeyindeki artış yeterli değildir. Uygun bir eğitim sonucu annelerin tamamlayıcı beslenme uygulamalarına doğru davranışların yansıması beklenmektedir (28).

Ülkemizde tamamlayıcı besinlere erken başlamak yaygın bir uygulamadır. Türkiye Nüfus ve Sağlık Araştırması 2018 raporuna göre 4-5 aylık bebeklerde

Tablo 5. Eğitim ve kontrol grubundaki annelerin tamamlayıcı besinlere tuz, baharat ve şeker ekleme durumlarının karşılaştırılması

\begin{tabular}{|c|c|c|c|c|c|c|}
\hline \multirow{2}{*}{ Tuz, baharat ve şşeker ekleme* } & \multicolumn{2}{|c|}{ Eğitim grubu $(n=42)$} & \multicolumn{2}{|c|}{ Kontrol grubu $(n=41)$} & \multirow{2}{*}{$\boldsymbol{X}^{2}$} & \multirow{2}{*}{$\mathbf{p}$} \\
\hline & $\mathrm{S}$ & $\%$ & S & $\%$ & & \\
\hline Tuz ekleme & 12 & 28.6 & 25 & 61.0 & 8.818 & 0.004 \\
\hline Baharat ekleme & 3 & 7.1 & 7 & 17.1 & 1.931 & 0.194 \\
\hline Şeker ekleme & 6 & 14.3 & 16 & 39.0 & 6.518 & 0.013 \\
\hline
\end{tabular}

*Tamamlayıcı beslenmeye başladıktan 3 ay sonra 
sadece anne sütü ile beslenme oranlarının \%14 olduğu belirtilmektedir (9). Ancak çalışmalarda doğum sonrası verilen eğitim ile annelerin bilgi düzeylerinin arttığı, emzirme ve tamamlayıcı beslenme uygulamalarında gelişmeler olduğu gösterilmektedir $(29,30)$. Bu çalışmada da annelerin tamamlayıcı beslenme uygulamalarını değerlendirmek amacıyla ilk olarak annelerin tamamlayıcı besinlere başlama zamanları kıyaslandığında, eğitim grubundaki annelerin çoğunluğunun (\%64.3) önerildiği şekilde tamamlayıcı beslenmeye 6. ayda başladığı, kontrol grubunda ise bu oranın \%17.1 olduğu görülmüştür. Ahmad et al. (31) tarafindan yapılan bir çalışmada da annelere verilen eğitim sonrası benzer şekilde eğitim grubunda tamamlayıcı besinlere 6. ayda başlama oranının \%68, kontrol grubunda ise \%16 olduğu belirlenmiştir. Ülkemizde yapılan benzer bir çalışmada ise eğitim sonrası eğitim grubundaki annelerin \%43'ünün, kontrol grubundaki annelerin ise \%23’ünün tamamlayıcı beslenmeye 6. ayda başladığı görülmüştür (32). Bu sonuçlar ve çalışmamızın sonuçları değerlendirildiğinde ülkemizde tamamlayıcı beslenmeye 6 . ayda başlama oranlarının düşük olduğu, ancak annelere bu konuda ayrıntılı bir eğitim verilmesi ile tamamlayıcı beslenmeye zamanında başlama oranlarının artırılabileceği sonucuna varılabilir.

Annelerin tamamlayıcı beslenmeye erken başlama sebeplerinin temelinde de bilgi eksikliği ve yanlış inanışlar yatmaktadır. $\mathrm{Bu}$ çalışmada annelerin tamamlayıcı besine erken başlama sebeplerinin başında bebeğin doymadığı düşüncesi, farklı tatlara alışması düşüncesi ve sütlerinin az geldiği düşüncesi gelmektedir. Literatürde de benzer şekilde anneler sütlerinin yetmediğini ve bebeğin doymadığını düşündükleri için ve bebeği farklı tatlara alıştırmak için tamamlayıcı beslenmeye erken başladıklarını belirtmişlerdir (14,16). Bu sebeplerin belirlenmesi ve eğitimlerde bu konular üzerine odaklanılması tamamlayıcı besinlere zamanında başlama oranlarının artmasını sağlayabilir.
Tamamlayıcı besinlere sadece zamanında başlamak yeterli değildir. Tamamlayıcı besinler bebeğin ayına ve fizyolojik durumuna uygun olması gerekmektedir (8). Optimal büyüme-gelişmenin sağlanması açısından bebek beslenmesinde tercih edilen besinlerin enerji yoğunluğunun yüksek olması, tüm elzem aminoasitleri, vitamin-mineralleri (demir, folik asit ve kalsiyum gibi) içermesi, tat-kıvam açısından bebeğe uygun olması önemlidir (33). Bu bağlamda annelerin bebeklerine ilk olarak verdikleri tamamlayıcı besinler sorgulanmıştır. Eğitim grubundaki anneler bebeğe ilk tamamlayıcı besin olarak genellikle yoğurt, meyve suyu/püresi, yumurta sarısı gibi besinleri vermeyi tercih ederken, kontrol grubundan az sayıda annenin bunlara ek olarak ilk tamamlayıcı besin olarak verilmesi uygun olmayan tam yumurta, yemek suları, bebek bisküvisi, bal-şeker gibi besinleri de tercih ettiği görülmüştür. Yapılan diğer çalışmalarda da çalışmamızla benzer şekilde annelerin bebeklerine ilk tamamlayıcı besin olarak daha çok meyve-sebze püresi ve yoğurt vermeyi tercih ettikleri görülmüştür $(14,19)$. Eğitimlerde annelere aylara göre bebeklere verilmesi önerilen besinler ve miktarları konusunda ayrıntılı, görsel sunularla bilgi verilebilir ve örnek tamamlayıcı beslenme tarifleri gösterilerek sunulabilir.

Tamamlayıcı besinlere tuz, şeker ve baharatların eklenmesi tamamlayıcı beslenme konusunda yapılan yanlış uygulamalardan biridir. Şeker ve şekerli besinler boş enerji kaynağıdır ve bebeğin beslenmesinde bir yarar sağlamamaktadır. Ayrıca ileri dönemde çocuklarda diş çürüklerine, iştahsızlığa ve yanlış beslenme alışkanlıklarının gelişmesine neden olabilmektedir (23). Erken yaşlarda aşırı tuz alımı ise ileri dönemlerde bebeğin tuzlu tatları daha fazla tercih etmesine ve arteriyel basincin artmasina neden olabilmektedir (34). Ayrıca bebeklerin böbrekleri henüz tam olarak gelişmediği için tamamlayıcı besinlerine eklenecek tuz böbrekler üzerinde de olumsuz etki oluşturabilmektedir (35). Baharatlar ise bebeklerde alerjik reaksiyonlara neden olabileceği için kullanımı konusunda dikkat etmek gerekmektedir (36). Bu çalışmada eğitim grubuna verilen tamamlayıcı 
beslenme eğitiminde tamamlayıcı besinlere tuz, şeker ve baharat eklemenin uygun olmadığı anlatılmıştır. Anneler tamamlayıcı besine başladıktan üç ay sonra bu durum sorgulanmış ve eğitim grubundaki annelerin tamamlayıcı besinlere tuz ve şeker ekleme durumlarının kontrol grubundakilerden daha düşük olduğu belirlenmiştir. $\mathrm{Bu}$ durum eğitimin bilgi düzeyindeki artışın yanı sıra, tamamlayıcı beslenme konusundaki bazı yanlış davranışlarını azaltma konusunda da yararlı olduğunu göstermektedir.

Bu çalışmanın güçlü yanları; ülkemizde literatürde sınırlı olan tamamlayıcı beslenme eğitimi konusuna odaklanmış olmasıdır. Annelerin henüz tamamlayıcı beslenmeye başlamadıkları dönemde çalışmaya dahil edilmesi de bir diğer güçlü yanıdır. Ancak annelerin tamamlayıcı beslenme konusundaki bilgi düzeylerini değerlendirmede kullanılan "Tamamlayıcı Beslenme Bilgi Düzeyi Anketi”nin geçerlik-güvenirliği yapılmış bir anket olmaması çalışmanın sınırlılıklarındandır.

Sonuç olarak, çocuk sağlığı izlemleri kapsamında poliklinikte verilen eğitim ile karşlaştırıldığında, yeterli süre ayrılarak ve görsel sunularla annelere ayrıntılı eğitim verildiğinde annelerin bilgi düzeyi artmış, buna bağlı olarak altıncı ayda tamamlayıcı besine başlama oranları yükselmiştir. Eğitim sonucunda annelerin bilgi düzeyinin artmasinın yanında tamamlayıcı beslenme ile ilgili bazı yanlış davranışların da azaldığı görülmüştür.

Tamamlayıcı beslenme dönemindeki hatalı davranışları önlemek için anneler tamamlayıcı besine başlamadan önce tamamlayıcı beslenme konusunda ayrıntılı eğitimler verilmeli, başladıklarında ise düzenli olarak danışmanlık hizmeti sunulmalıdır. Ayrıca bebeğinin doymadığını, sütünün yetersiz olduğunu düşünen ve tamamlayıcı besinlere geçişte problem yaşayan anne ve bebekler diyetisyen tarafından yakından izlenmelidir. Daha geniş kapsamlı eğitim çalışmaları yapılarak annelerin bilinç düzeyi artırılmalıdır.

Çıkar çatışması - Conflict of interest: Yazarlar çıkar çatışması olmadığını beyan ederler. - The authors declare that they have no conflict of interest.

\section{KAYNAKLAR}

1. Victora CG, Bahl R, Barros AJD, França GVA, Horton S, Krasevec J, et al. Breastfeeding in the 21st century: Epidemiology, mechanisms, and lifelong effect. Lancet. 2017;387(10017):475-90.

2. Rollins NC, Bhandari N, Hajeebhoy N, Horton S, Lutter CK, Martines JC, et al. Why invest, and what it will take to improve breastfeeding practices? Lancet. 2016;387(10017):491-504.

3. Stuebe A. The risks of not breastfeeding for mothers and infants. Rev Obstet Gynecol. 2009;2(4):222-31.

4. WHO. Complementary feeding. Available at: https:// www.who.int/nutrition/topics/complementary_feeding/ en/ Accessed September 1, 2019.

5. Gür E. Tamamlayıcı beslenme. Türk Ped Ars. 2006;41:1818.

6. WHO/UNICEF. Global strategy for infant and young child feeding. 2003. Available at: https://apps.who.int/ iris/ bitstream/ handle/ 10665/42590/ 9241562218.pdf; jsessionid $=$ DA0E9323846C5625B858A8595BBD6F06? sequence=1 Accessed September 1, 2019.

7. Imdad A, Yakoob MY, Bhutta ZA. Impact of maternal education about complementary feeding and provision of complementary foods on child growth in developing countries. BMC Public Health. 2011;11(3):25-38.

8. WHO. Report of Informal Meeting to Review and Develop Indicators for Complementary Feeding. 2002. Available at: https://www.who.int/nutrition/publications/report of_informal_meeting_for_cf.pdf Accessed September 12, 2019.

9. Hacettepe Üniversitesi Nüfus Etütleri Enstitüsü. Türkiye Nüfus ve Sağlık Araştırması 2018. Ankara: Elma Teknik Basım Matbaacılık Ltd. Şti; 2019. 310 s. Rapor No.: NEEHÜ.19.01.

10. United States Department of Agriculture Food and Nutrition Service. Infant Nutrition and Feeding. 2009. Available at: https://wicworks.fns.usda.gov/wicworks/ Topics/FG/CompleteIFG.pdf Accessed September 9, 2019.

11. WHO. Essential nutrition actions: Improving maternal, newborn, infant and young child health and nutrition. 2013. Available at: www.who.int/about/licensing/ Accessed September 9, 2019.

12. Guldan GS, Fan H-C, Ma X, Ni Z-Z, Xiang X, Tang M-Z. Culturally appropriate nutrition education improves infant feeding and growth in Rural Sichuan, China. J Nutr. 2000;130(5):1204-11.

13. Shi L, Zhang J. Recent evidence of the effectiveness of educational interventions for improving complementary feeding practices in developing countries. J Trop Pediatr. 2011;57(2):91-8.

14. Yılmazbaş P, Kural B, Uslu A, Sezer GM, Gökçay G. 
Annelerin gözünden ek besinlere başlama nedenleri ve annelerin mamalar hakkındaki düşünceleri. İst Tıp Fak Derg. 2015;78(3):76-82.

15. Kondolot M, Yalçin SS, Yurdakök K. Sadece anne sütü alım durumuna etki eden faktörler. Çocuk Sağlığı ve Hast Derg. 2009;52(3):122-7.

16. Bülbül S, Kılınçkaya MF. 0- 2 yaş grubu bebeklerin anne sütü ile beslenme durumları ve etkileyen faktörler. Kırıkkale Üniversitesi Tıp Fakültesi Derg. 2014;15(1):1520.

17. Sivri BB, Özpulat F, Büyükmumcu M. 0-6 aylık bebeği olan annelerin katı gıdaya geçiş süreci ve emzirmeye ilişkin bilgi ve uygulamaları. Acıbadem Üniversitesi Sağllk Bilim Derg. 2014;5(1):59-65.

18. Eker A, Yurdakul M. Annelerin bebek beslenmesi ve emzirmeye ilişkin bilgi ve uygulamaları. STED. 2006;15(9):158-63.

19. İşgör A, Çifçili S, Akman M, Tüzün S, Ünalan P. Anneler için tamamlayıcı beslenme hakkında bir eğitim çalışması. Turkish Fam Physician. 2010;1(3):79-91.

20. Bağ Ö, Yaprak I, Halıcıoğlu O, Parlak Ö, Harputluoğlu $\mathrm{N}$, Astarcıoğlu G. Maternal knowledge on breast milk and psychosocial factors influencing exclusive breastfeeding. Tepecik Eğit Hast Derg. 2006;16(2):63-70.

21. Pekcan G. Beslenme durumunun saptanması. Ankara: Sağlık Bakanlığı Yayınları, 2008. 50 s. Yayın No: 726.

22. American Academy of Pediatrics. Breastfeeding and the use of human milk. Pediatrics. 2012;129(3):e827-e841.

23. Köksal G, Gökmen-Özel H. Bebek beslenmesi. Ankara: Sağlık Bakanlığı Yayınları, 2008. 31 s. Yayın No:726.

24. Beşer ÖF, Çullu Çokuğraş F. Zamanında doğmuş sağlıklı çocuklarda tamamlayıcı beslenme. Klin Tıp Derg. 2018;10(6):6-12.

25. Mulualem D, Henry CJ, Berhanu G, Whiting SJ. The effectiveness of nutrition education: Applying the Health Belief Model in child-feeding practices to use pulses for complementary feeding in Southern Ethiopia. Ecol Food Nutr. 2016;55(3):308-23.

26. Bhutta ZA, Das JK, Rizvi A, Gaffey MF, Walker N, Horton $S$, et al. Evidence-based interventions for improvement of maternal and child nutrition: What can be done and at what cost? Lancet. 2013;382(9890):452-77.

27. Vazir S, Engle P, Balakrishna N, Griffiths PL, Johnson $\mathrm{SL}, \mathrm{Creed-Kanashiro} \mathrm{H}$, et al. Cluster-randomized trial on complementary and responsive feeding education to caregivers found improved dietary intake, growth and development among rural Indian toddlers. Matern Child Nutr. 2013;9(1):99-117.

28. Abrantes Cândido N, Maia de Sousa T, Caroline dos Santos L. Effectiveness of different interventions in public nurseries based on food and nutrition education: promoting breast-feeding and healthy complementary feeding. Public Health Nutr. 2018;21(13):2454-61.

29. Bhutta ZA, Ahmed T, Black RE, Cousens S, Dewey $\mathrm{K}$, Giugliani E, et al. What works? Interventions for maternal and child undernutrition and survival. Lancet. 2008;371(9610):417-40.

30. Nikièma L, Huybregts L, Martin-Prevel Y, Donnen P, Lanou H, Grosemans J, et al. Effectiveness of facilitybased personalized maternal nutrition counseling in improving child growth and morbidity up to 18 months: A cluster-randomized controlled trial in rural Burkina Faso. PLoS One. 2017;12(5):1-26.

31. Ahmad MO, Sughra U, Kalsoom U, Imran M, Hadi U. Effect of antenatal counselling on exclusive breastfeeding. J Ayub Med Coll Abbottabad. 2012;24(2):116-9.

32. Aksu H, Küçük M, Düzgün $G$, The effect of postnatal breastfeeding education/ support offered at home 3 days after delivery on breastfeeding duration and knowledge: a randomized trial. J Matern Fetal Neonatal Med. 2010;24(2):354-61.

33. Abeshu MA, Lelisa A, Geleta B. Complementary feeding: review of recommendations, feeding practices, and adequacy of homemade complementary food preparations in developing countries - lessons from Ethiopia. Front Nutr. 2016;3(41):1-9.

34. Edwards DG, Farquhar WB. Vascular effects of dietary salt. Curr Opin Nephrol Hypertens. 2015;24(1):8-13.

35. Action on Salt. Available at: http://www.actiononsalt.org. uk/salthealth/children/ Accessed September 28, 2019.

36. Öztürk M, Besler HT. Besin Alerjileri. Ankara: Sağllk Bakanlığı Yayınları, 2008. 24 s. Rapor No:727. 